\title{
Motives for Early-Stage Entrepreneurship in Modern Economies
}

\author{
I.S. Pinkovetskaia ${ }^{1}$, T.V. Gromova ${ }^{2}$, and I.N. Nikitina, ${ }^{2, *}$ \\ *Corresponding author: i.n.nikitina@gmail.com. \\ ${ }^{1}$ Ulyanovsk State University, Ulyanovsk, Russia \\ ${ }^{2}$ Samara State University of Economics, Samara, Russia
}

\begin{abstract}
The relevance of the study is due to the important role played by small and individual entrepreneurship in the vast majority of modern national economies. The aim of the study is to assess the indicators describing the ratio of voluntary, highly demanding and necessity-driven entrepreneurs in the total number of start-ups. The results of the Global Entrepreneurship Monitor project for 2018 were used as input data. Modeling of empirical data and evaluation of differentiation of the considered parameters was based on the development of normal distribution density functions. According to the results of modeling average values and change intervals of specific indicators were established. The originality of the work is associated with the assessment of the share of voluntary, highly demanding and necessity-driven entrepreneurs in the total number of early-stage entrepreneurs in 48 countries. The novelty of the study is due to the assessment of indicators characterizing the current motivation of entrepreneurs, as well as the ratio of the above mentioned indicators. The results of the study can be used in the formation of an entrepreneurial climate aimed at the development of a highly demanding business.
\end{abstract}

Keywords: entrepreneurship, motivation, countries, voluntary entrepreneurs, necessity-driven entrepreneurs, highly demanding entrepreneurs.

\section{Introduction}

Entrepreneurship plays an important role in modern economy. It provides a significant increase in the production of goods, operations and services in the vast majority of countries, creates new jobs, increases the level of competitiveness and innovation. Theoretical work and empirical research confirm that entrepreneurship is a key factor in the development of national economies. Thus, the paper [1] emphasizes that earlier industrial policy was aimed at the creation and growth of state-owned companies, and now such policy should be based on partnership between entrepreneurs and the state. Moreover, the relationship between entrepreneurs and the state depends on the level of economic development of a particular country. The article [2] considers how internal and external factors affect the development of small and medium enterprises.

Surveys of Global Entrepreneurship Monitor projects that have been conducted over the past 20 years are of great importance in the study of modern entrepreneurship. In 2018, a survey of working-age adults produced data that characterize indicators of entrepreneurial activity in 48 countries, including data on motivation of early-stage entrepreneurs [3]. Such entrepreneurs are adults (18-64 years) who at the time of the survey are in the process of starting a business or owning a business for less than 3.5 years.

The current methodology divides early-stage entrepreneurs into three main types based on their motives. The first type includes voluntary entrepreneurs. They are adult citizens who use the existing conditions and opportunities to benefit from creating their own business compared to employment. These advantages include the improvement of their financial situation through their own work, independence and autonomy in activities, improving social status, the possibility of self-realization and creative activity. Voluntary entrepreneurs include also the so-called highly demanding entrepreneurs who are oriented towards greater independence and the desire to earn more money than hired labor. They form the second type of motivation of entrepreneurs. The third type includes necessity-driven entrepreneurs (entrepreneurs by necessity). They include adult citizens who do not have any income and therefore start business because of the lack of other opportunities for making money. Motivation of entrepreneurs determines the features of the approach to entrepreneurship. Therefore, many of the necessity-driven entrepreneurs, with the appearance of employment opportunities for hired work prefer to stop business. Their business has a low survival rate. Accordingly, the short-term nature of their activities causes disinclination to invest in their business development. This is the most significant difference between voluntary (including highly demanding) entrepreneurs and necessity-driven entrepreneurs. Voluntary entrepreneurs focus on the development and improvement of business, getting the maximum positive effect from it. The data from the Global Entrepreneurship Monitor project show that voluntary entrepreneurs are more likely to explore new markets, create innovative products and services, and plan to increase the jobs. The share of voluntary, highly demanding and necessity-driven entrepreneurs in the total number of early-stage entrepreneurs is used as indicators of motivation.

Over the past decade, a number of studies have been conducted by foreign and domestic scientists related to the study of the motivation of entrepreneurs. The most interesting among them are the following studies. The article [4] analyzes data from a survey of entrepreneurs in the United States and 32 countries in Europe and Asia. Significant differences between voluntary and necessity-driven business owners in terms of socio-economic characteristics, 
personality and perception of entrepreneurship support are shown. In [5] it is proved that the higher degree of economic development of countries, measured by the gross domestic product per capita, positively correlates with the level of voluntary motivation of entrepreneurial activity. The article [6] examines the relationship between the development of the theory of entrepreneurship, and the motives of people making efforts to start their own business. The results of the study [7] show that many of those who at the initial stage were necessity-driven entrepreneurs in the UK, at the next stages of the development of their business changed motivation and moved to voluntary entrepreneurs group. The work [8] demonstrates that entrepreneurs are characterized by a higher level of satisfaction with their activities than employees.

The article [9] concludes that potential entrepreneurs in Russia are aimed at self-assertion. However, doing business to increase self-esteem and recognition is difficult because public authorities do not provide support for entrepreneurial activity of the population. The analysis of the published works shows that the studies have not paid sufficient attention to the comprehensive assessment of the motivation indicators of early-stage entrepreneurs in modern economy.

\section{Methods}

The article is devoted to the analysis of levels of motivation for entrepreneurship in the economy of modern countries. In this case, the data of the Global Entrepreneurship Monitor project for 2018 are used.

The study examined the following indicators characterizing the participation of adults in entrepreneurial activity at its initial stage in 48 countries:

- the share of voluntary entrepreneurs in the total number of early-stage entrepreneurs;

- the share of highly demanding entrepreneurs in the total number of early-stage entrepreneurs;

- the share of necessity-driven entrepreneurs in the total number of early-stage entrepreneurs.

In addition, the following indicators that describe the prevailing relationships of the above mentioned motives for entrepreneurship were evaluated:

- the ratio of the share of voluntary entrepreneurs to the share of necessity-driven entrepreneurs in each country;

- the ratio of the share of highly demanding entrepreneurs to the share of necessity-driven entrepreneurs in each country.

Assessment of the above indicators was based on the construction of density functions of the normal distribution. The construction of such functions, as shown by studies conducted by the authors, allows obtaining unbiased characteristics of the studied economic processes. The methodology of using density functions of normal distribution for estimation of specific and relative indices is given in the article [10].

Spatial data describing proportions and ratios for each of the 48 countries were considered as input data, respectively.

The study tested the following two hypotheses:

- indicators characterizing the motivation for early-stage entrepreneurship have a significant differentiation across countries;

- in most countries, voluntary and highly demanding entrepreneurs predominate in the early-stages of entrepreneurial activity.

\section{Results}

\subsection{Results of a computational experiment}

This article presents the models developed by the authors. The development of these models was based on information collected during the survey on the Global Entrepreneurship Monitor project in 2018. As models, we have developed dependencies characterizing the normal distribution of the studied parameters. Such functions $(y)$ describing the share of entrepreneurs belonging to each of the above mentioned types of entrepreneurs $(x, \%)$ in the total number of early-stage entrepreneurs are given below:

- the share of voluntary entrepreneurs, $\%$

$$
y_{1}\left(x_{1}\right)=\frac{390.00}{9.82 \times \sqrt{2 \pi}} \cdot e^{\frac{-\left(x_{1}-71.69\right)^{2}}{2 \times 9.82 \times 9.82}}
$$

- the share of highly demanding entrepreneurs, $\%$

$$
y_{2}\left(x_{2}\right)=\frac{357.02}{11.89 \times \sqrt{2 \pi}} \cdot e^{\frac{-\left(x_{2}-46.93\right)^{2}}{2 \times 11.89 \times 11.89}}
$$

- the share of necessity-driven entrepreneurs, \% 


$$
y_{3}\left(x_{3}\right)=\frac{377.14}{10.36 \times \sqrt{2 \pi}} \cdot e^{\frac{-\left(x_{3}-23.14\right)^{2}}{2 \times 10.36 \times 10.36}}
$$

In addition, normal distribution functions $(y)$, describing the relationship of the established indicators $(x)$ in each country were developed. They are listed below:

- the ratio of the share of voluntary entrepreneurs to the share of necessity-driven entrepreneurs

$$
y_{4}\left(x_{4}\right)=\frac{88.01}{2.16 \times \sqrt{2 \pi}} \cdot e^{\frac{-\left(x_{4}-3.85\right)^{2}}{2 \times 2.16 \times 2.16}}
$$

- the ratio of the share of highly demanding entrepreneurs to the share of necessity-driven entrepreneurs

$$
y_{5}\left(x_{5}\right)=\frac{51.57}{1.50 \times \sqrt{2 \pi}} \cdot e^{-\frac{\left(x_{5}-2.48\right)^{2}}{2 \times 1.50 \times 1.50}}
$$

The quality of the developed models was assessed using three tests. The computational experiment showed that estimated values by Kolmogorov-Smirnov test range from 0.041 to 0.110 . These values are significantly less than the tabulated value of 0.152 (significance level 0.05). The estimated values by Pearson test range from 0.038 to 4.334 that is less than the tabulated value (9.49). The estimated values by Shapiro-Vilka test exceed the tabulated value 0.93 (significance level 0.01). Econometric analysis of these 3 tests showed high quality of each of the functions (1) -(5).

\subsection{Assessment of early-stage entrepreneurs' motivation}

Using density functions of the normal distribution (1) - (5), characteristics were obtained that show the existing patterns of prevailing motivation for early entrepreneurial activity in the economies of different countries in modern conditions.

The main indicators of functions (1) - (5) are given in the table. The average values are shown in column 2. Column 3 of the table shows the change interval of the indicators under consideration typical for most $(68 \%)$ countries.

Table 1. Indicators characterizing motivation for early-stage entrepreneurship.

\begin{tabular}{|c|c|c|}
\hline Indicators & Average value & $\begin{array}{c}\text { Change interval of values } \\
\text { typical for most countries }\end{array}$ \\
\hline 1 & 2 & 3 \\
\hline Share of voluntary entrepreneurs, $\%$ & 71.69 & $61.87-81.51$ \\
\hline $\begin{array}{c}\text { Share of highly demanding } \\
\text { entrepreneurs, } \%\end{array}$ & 46.93 & $35.04-57.82$ \\
\hline Share of necessity-driven entrepreneurs, $\%$ & 23.14 & $12.78-33.50$ \\
\hline $\begin{array}{c}\text { Ratio of the share of voluntary } \\
\text { entrepreneurs to the share of necessity- } \\
\text { driven entrepreneurs }\end{array}$ & 3.85 & $0.98-3.98$ \\
\hline $\begin{array}{c}\text { Ratio of the share of highly demanding } \\
\text { entrepreneurs to the share of necessity- } \\
\text { driven entrepreneurs }\end{array}$ & 2.48 & \\
\hline
\end{tabular}

Source: Authors.

The data in column 2 allows concluding that in 2018 the average country-specific share of voluntary entrepreneurs amounted to almost $72 \%$. Therefore, voluntary motivation was prevailing. For most countries, this indicator ranged from $62 \%$ to $81 \%$ (column 3). The indicators that went beyond the upper boundary of this change interval were noted in Poland, Switzerland, Colombia, Panama, Cyprus, Great Britain and Greece. The indicators that went beyond the lower boundary of this change interval were observed in Brazil, Iran, Angola, Russia, Egypt and India. However, only in Egypt and India the figure was less than 50 per cent (47.5 per cent and 43.2 per cent, respectively).

The average share of highly demanding entrepreneurs in the countries under consideration was about 47 per cent. That is, almost half of all early-stage entrepreneurs in the analyzed countries regarded themselves as highly demanding. For most countries, the figure ranged from 35 per cent to 58 per cent. The indicators above the upper boundary of the interval shown in column 3 of table 1 occurred in 2018 in Panama, the Netherlands, Switzerland, South Korea, Chile, Cyprus, France, Thailand. Lower values of the share of highly demanding entrepreneurs from $25.4 \%$ to $31.6 \%$ were observed in India, China, Egypt, Bulgaria, Turkey, Italy and Russia.

The average share of necessity-driven entrepreneurs across 48 countries, in the total number of early-stage entrepreneurs was $23 \%$. At the same time, in most countries this indicator ranged from $12.8 \%$ to $33.5 \%$. Values above the upper boundary of this range were noted in Egypt, India, Russia, Angola, Guatemala, Brazil, Iran, Lebanon. Values 
beyond the lower end of the range (namely, from $12 \%$ to $7 \%$ ) were observed in Luxembourg, Cyprus, Italy, Sweden, the Netherlands, Poland, the USA, and Switzerland. It is interesting to note that in countries such as Russia, Japan, Germany, and Italy, a low level of early-stage entrepreneurship and a low share of entrepreneurs who ceased operations were simultaneously observed.

The ratio of voluntary to necessity-driven entrepreneurs averaged 3.8 in all the countries under consideration. The trend of exceeding the share of voluntary entrepreneurs over necessity-driven ones was observed in 46 countries. In one country only (India) the figure was 0.9 . Values below the lower end of the range shown in column 3 of table 1 , but more than 1.0 occurred in Guatemala, Brazil, Angola, Russia and Egypt. The highest values of the ratio of the share of voluntary and necessity-driven entrepreneurs (from 11.8 to 6.5 ) were observed in Switzerland, Poland, the USA, the Netherlands, Sweden, Cyprus, Italy, Colombia, Luxembourg, Panama and the UK.

The ratio of the share of highly demanding entrepreneurs to the share of necessity-driven entrepreneurs was 2.5 on average in all the countries under consideration. The trend of exceeding the share of highly demanding entrepreneurs over necessity-driven ones was observed in 43 countries. In five countries, the figure was less than 1.0. The highest values of the ratio of the share of highly demanding and necessity-driven entrepreneurs (from 9.1 to 4.4) were observed in economically developed countries, such as Switzerland, Poland, the USA, the Netherlands, Sweden, Cyprus, Italy, Luxembourg, Panama and the UK.

As follows from the data of column 3, in 2018 there was a significant differentiation of all five analyzed indicators by countries. This is due to social, economic, demographic, historical features of the development of specific countries.

In general, the above analysis confirmed the correctness of the hypotheses about the significant differentiation of the considered indicators by countries and the excess of the share of both voluntary and highly demanding entrepreneurs over the share of necessity-driven entrepreneurs in most countries.

\section{Conclusion}

The scientific novelty of the research findings includes the following:

- the indicators describing the existing levels of motivation for early-stage entrepreneurship, using the density functions of the normal distribution are assessed;

- the indicators reflecting the correlation of motivation levels are evaluated;

- high quality of approximation of initial data by functions (1) - (5) is proved;

- average values of the considered indicators for 48 countries included in the Global Entrepreneurship Monitor project are established;

- the prevalence in most countries of voluntary and highly demanding entrepreneurs over necessity-driven is confirmed;

- significant differentiation of indicators by countries is proved;

- the countries with high and low levels of the considered indicators are presented.

The models developed in the research process can be applied by government bodies in substantiating strategic documents for the development and improvement of entrepreneurship.

\section{References}

1. Z.J. Acs, W. Naudé, Entrepreneurship, stages of development, and industrialization. WIDER Working Paper 2011/080 (UNU-WIDER, Helsinki, 2011).

2. P.D. Gupta, S. Guha, S.S. Krishnaswami, Firm growth and its determinants. Journal of Innovation and Entrepreneurship, 2, 15 (2013).

3. N. Bosma, D. Kelley, Global Entrepreneurship Monitor. 2018-2019 Global Report. Global Entrepreneurship Research Association (GERA) (2019). URL: https://www.gemconsortium.org/report. Accessed: 25.09.2019.

4. P. van der Zwan, R. Thurik, I. Verheul, J. Hessels, Factors influencing the entrepreneurial engagement of opportunity and necessity entrepreneurs. Eurasian Business Review, 6(3), 273-295 (2016).

5. M. Benz, B.S. Frey, The value of doing what you like: Evidence from the self-employed in 23 countries. Journal of Economic Behavior \& Organization, 68, 445-455 (2008).

6. G. Segal, D. Borgia, J. Schoenfeld, The motivation to become an entrepreneur. International Journal of Entrepreneurial Behaviour \& Research, 11(1), $42-57$ (2005).

7. R.L. De Silva, Business start-up and growth motives of entrepreneurs: A case in Bradford, United Kingdom. Manchester Business School Working Paper, $597 \quad$ (2010). URL: https://www.econstor.eu/bitstream/10419/50712/1/656920246.pdf. Accessed:09.09.2019.

8. D. Bobera, B. Lekovic, N. Berber, The relationship between motives of entrepreneurial behavior and venture maturity. Industrija, 45(1), 81-98 (2017).

9. N.V. Ket'ko, O.E. Akimova, Researching the motivational preferences of entrepreneurs for Russian small business development. Economic Analysis: Theory and Practice, 9, 27-38 (2016). [in Rus.].

10. I.S. Pinkovetskaia, I.N. Nikitina, T.V. Gromova, The role of small and medium entrepreneurship in the economy of Russia. Montenegrin Journal of Economics, 14 (3), 177-188 (2018). 